Note

\section{Pyroglutamyl-arginine, N-Terminal Tryptic Peptide of Wheat Germ Agglutinin}

\author{
Yoshiho NAGATA \\ Division of Enzymology, \\ Institute of Applied Microbiology, \\ The University of Tokyo, \\ Tokyo 113, Japan
}

Received August 8, 1984

Wheat germ agglutinin (WGA) has been used extensively as a tool in studies on the characterization and isolation of cell surface components. ${ }^{1}$ WGA is one of the most extensively studied plant lectins: Early physicochemical studies on $\mathrm{WGA}^{2 \sim 4)}$ have revealed that WGA consists of two identical subunits which have a molecular weight of approximately 17,000 and a four-fold structural domain repeat. The amino acid composition of WGA indicates an unusually high content of cystine and glycine. The total number of amino acid residues is estimated to be 165. The N-terminal residue of WGA is blocked. Two to four isolectins are present depending on the source of the wheat germ. This is presumably due to the polyploid nature of wheat.

Although the primary ${ }^{5)}$ as well as the three-dimensional structure $^{6,7)}$ of WGA has been elucidated, no precise characterization of the $\mathrm{N}$-terminal residue has been reported yet. ${ }^{5)}$ In this communication, isolation and characterization of the N-terminal tryptic peptide of WGA is described.

WGA was isolated from raw wheat germ (kindly supplied by Nippon Flour Mills Co., Ltd.) as described previously ${ }^{8)}$ and further purified by chitin-affinity chromatography. ${ }^{9)}$ A tryptic digest of WGA was obtained by treating performic acid oxidized WGA with TPCK-trypsin (Sigma) at $37^{\circ} \mathrm{C}$ for $16 \mathrm{hr}$. The tryptic digest was fractionated by ion-exchange chromatography using $A G$ $50 \mathrm{~W} \times 2$. As shown in Fig. 1, seven peaks were obtained. Identification of the $\mathrm{N}$-terminal residue was done for each peak fraction. Since no PTH-amino acid was detected for fraction 4 by Edman degradation, this fraction must contain the $\mathrm{N}$-terminal tryptic peptide of WGA. Yield of the peptide $\mathrm{T}-4$ was $84 \%$.

In order to characterize this peptide (T-4), it was treated with Bacillus amyloliquefaciens pyroglutamyl peptidase (PG peptidase: EC 3.4.19.3.; a kind gift from Dr. D. Tsuru) ${ }^{10)}$ In Table I, results of amino acid analysis and PG peptidase treatment of this peptide together with authentic L-pyroglutamyl-L-alanine (pGlu-Ala) (Cyclo Chemical Corp.) as a control are shown. As seen in the Table, after acid hydrolysis, equi-molar amounts of Glu

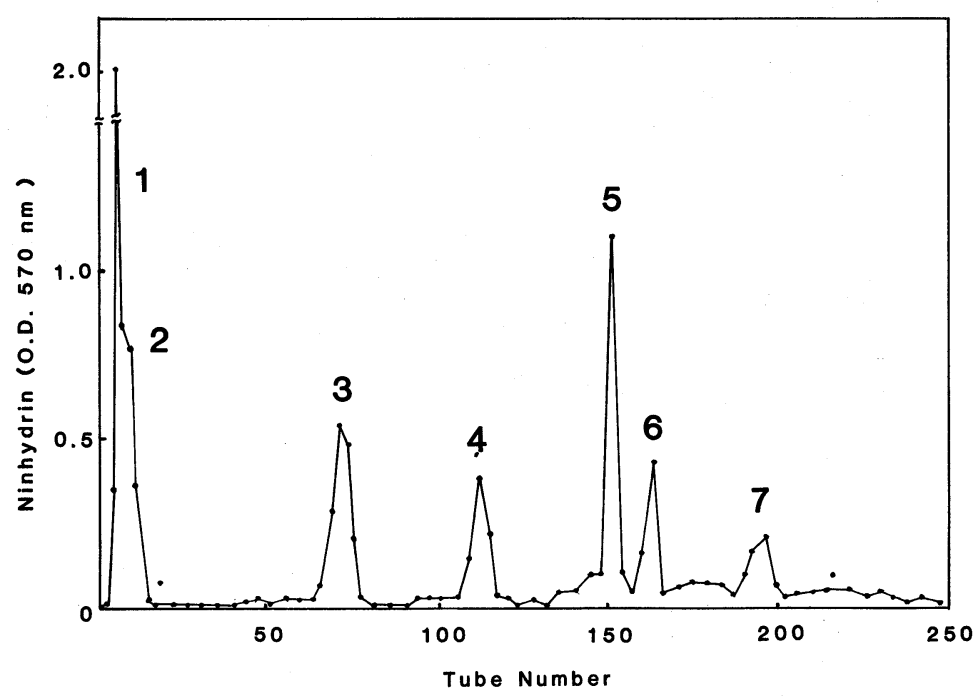

FIg 1. Separation of Tryptic Digest of WGA by Ion Exchange Chromatography.

The tryptic digest of performic acid oxidized WGA was applied to an AG $50 \mathrm{~W} \times 2$ column $(0.8 \times 70 \mathrm{~cm})$, equilibrated with $0.1 \%$ pyridine-acetate, $\mathrm{pH} 3.80$. A gradient elution with increasing $\mathrm{pH}$ and ionic strength was established with a nine-chamber apparatus, and the composition of buffers was the same as described by Canfield. ${ }^{14)}$ The elution was carried out at $37^{\circ} \mathrm{C}$ at a flow rate of $20 \mathrm{ml}$ per hr and fractions of $3 \mathrm{ml}$ were collected. Aliquots from alternate tubes were assayed by the ninhydrin reaction. 
Table I. Amino Acid Composition and PG Peptidase Treatment with PePtide T- $4^{a}$

\begin{tabular}{|c|c|c|c|c|c|}
\hline & & \multicolumn{2}{|c|}{ pGlu-Ala } & \multicolumn{2}{|c|}{ Peptide T-4 } \\
\hline & & $\begin{array}{l}\text { Glu } \\
\text { (nm }\end{array}$ & (nmol) & $\begin{array}{l}\text { Glu } \\
\quad(\mathrm{nm}\end{array}$ & $\begin{array}{l}\text { Arg } \\
\text { ol) }\end{array}$ \\
\hline A. & $\begin{array}{l}\text { Amino acid } \\
\text { composition }\end{array}$ & $\begin{array}{l}79.68 \\
(0.99)\end{array}$ & $\begin{array}{l}80.12 \\
(1.00)\end{array}$ & $\begin{array}{l}70.32 \\
(1.03)\end{array}$ & $\begin{array}{l}68.06 \\
(1.00)\end{array}$ \\
\hline B. & $\begin{array}{l}\text { Pyroglutamyl } \\
\text { peptidase }\end{array}$ & $\begin{array}{c}<0.01 \\
(0)\end{array}$ & $\begin{array}{l}76.77 \\
(0.96)\end{array}$ & $\begin{array}{c}<0.01 \\
(0)\end{array}$ & $\begin{array}{l}65.43 \\
(0.96)\end{array}$ \\
\hline
\end{tabular}

${ }^{a}$ A: Approximately eighty nmol each of peptide T-4 and authentic pGlu-Ala were hydrolyzed with $6 \mathrm{~N} \mathrm{HCl}$ in a sealed, evacuated tube at $105^{\circ} \mathrm{C}$ for $24 \mathrm{hr}$ and analyzed in a JEOL amino acid analyzer JLC 6AH.

B: The same amount of the samples was treated with PG peptidase in $50 \mathrm{~mm}$ phosphate buffer, $\mathrm{pH}$ 7.3 , containing $30 \mathrm{~mm} 2$-mercaptoethanol and $1 \mathrm{~mm}$ EDTA for $16 \mathrm{hr}$ at $37^{\circ} \mathrm{C}^{12)}$ and the digest was assayed by the amino acid analyzer.

and Arg from the peptide T-4 were detected. By treatment with PG peptidase, only Arg from the peptide T-4 was quantitatively liberated. These results strongly suggest that the peptide exists in the form of pGlu-Arg. To confirm this, reduced and carboxymethylated WGA was treated with PG peptidase and directly sequenced by the automated procedure using a JEOL Sequence Analyzer under the conditions described previously. ${ }^{11)}$ A new N-terminal residue, Arg, was detected by an amino acid analyzer JLC 6AH (JEOL) after back hydrolysis of the thiazolinone derivative from the first cycle of sequence analysis with $5.7 \mathrm{~N} \mathrm{HCl}$ containing $0.1 \% \mathrm{SnCl}_{2}$ at $150^{\circ} \mathrm{C}$ for $4 \mathrm{hr}^{12)}$ ) Yield of $\mathrm{Arg}$ was estimated to be approximately $30 \%$. No other amino acids in significant amounts were detected. The new N-terminal residue was followed by $\mathrm{Cys}(\mathrm{Cm})-\mathrm{Gly}-\mathrm{Glx}-\mathrm{GlX}$ Gly-.

Specificity of PG peptidase for amino acids penultimate to a terminal pyroglutamic acid residue has been investigated. ${ }^{13)}$ The results presented in this communication have revealed that the N-terminal residue of WGA is pGlu and the enzyme is able to remove this residue from $\mathrm{S}$ carboxymethylated WGA.

Acknowledgments. The author thanks Dr. D. Tsuru for the gift of pyroglutamyl peptidase, and Dr. C. S. Wright for communicating her sequence data before publication. The author expresses his gratitude to Drs. A. Tsugita and M. M. Burger for helpful discussion, and to Ms. M. Harada for preparation of the manuscript.

\section{REFERENCES}

1) I. J. Goldstein and C. E. Hayes, Adv. Carbohydr. Chem. Biochem., 35, 127 (1978).

2) Y. Nagata and M. M. Burger, J. Biol. Chem., 249, 3116 (1974).

3) R. H. Rice and M. E. Etzler, Biochemistry, 14, 4093 (1975).

4) C. S. Wright, J. Mol. Biol., 111, 439 (1977).

5) C. S. Wright, F. Gavilanes and D. L. Peterson, Biochemistry, 23, 280 (1984).

6) C. S. Wright, C. Keith, Y. Nagata, M. M. Burger and R. Langridge, J. Mol. Biol., 87, 843 (1974).

7) C. S. Wright, J. Mol. Biol., 145, 453 (1981).

8) Y. Nagata, A. R. Goldberg and M. M. Burger, Methods in Enzymol., 32, 611 (1974).

9) R. Bloch and M. M. Burger, Biochem. Biophys. Res. Commun., 58, 13 (1974).

10) D. Tsuru, K. Fujiwara and K. Kado, J. Biochem., 84, 467 (1978).

11) Y. Nagata, S. Suga and B. Maruo, Agric. Biol. Chem., submitted.

12) E. Mendez and C. Y. Lai, Anal. Biochem., 68, 47 (1975).

13) K. Fujiwara, R. Kobayashi and D. Tsuru, Biochim. Biophys. Acta, 570, 140 (1979).

14) R. E. Canfield, J. Biol. Chem., 238, 2691 (1963). 